\title{
BILANGAN RAINBOW CONNECTION UNTUK GRAF KOMPLEMEN
}

\author{
RENI WIJAYA \\ Program Studi Magister Matematika, \\ Fakultas Matematika dan Ilmu Pengetahuan Alam, Universitas Andalas, \\ Kampus UNAND Limau Manis Padang, Indonesia, \\ ar3n_jaya@yahoo.com
}

\begin{abstract}
Abstrak. Misalkan terdapat dua titik $u, v$ pada graf $G$. Suatu $u$ - $v$ path, dinotasikan dengan ${ }_{u} P_{v}$ di $G$, dikatakan rainbow path jika tidak terdapat dua sisi di $P$ yang memiliki warna sama. Suatu pewarnaan sisi di $G$ dikatakan rainbow connected jika setiap dua titik yang berbeda dihubungkan oleh rainbow path. Bilangan rainbow connection dari graf terhubung $G$, ditulis $r c(G)$, didefinisikan sebagai banyaknya warna minimal yang diperlukan untuk membuat $G$ bersifat rainbow connected. Pada tulisan ini dibahas tentang bilangan rainbow connection untuk komplemen dari graf lingkaran $C_{n}$ dengan $n \geq 6$ dan graf buku $B_{2}$.
\end{abstract}

Kata Kunci: Graf komplemen, graf lingkaran, graf buku

\section{Pendahuluan}

Perkembangan teori graf saat ini tidak hanya secara teoritis, tetapi juga secara aplikatif seperti dalam ilmu jaringan komunikasi, transportasi, ilmu komputer, musik, dan ilmu-ilmu lainnya. Salah satu topik yang dipelajari dalam teori graf adalah rainbow connection.

Konsep rainbow connection pada graf pertama kali diperkenalkan oleh Chartrand dkk, pada tahun 2006 [4]. Misalkan $G$ adalah graf terhubung tak trivial, didefinisikan pewarnaan sisi $c: E(G) \rightarrow\{1,2, \cdots, k\}, k \in \mathbb{N}$, dimana sisi yang bertetangga boleh memiliki warna yang sama. Suatu path adalah jalan yang semua titik berbeda. Suatu (u-v) path $P$ di $G$ dikatakan rainbow path jika tidak ada dua sisi di $P$ yang memiliki warna sama. Suatu pewarnaan sisi di $G$ dikatakan rainbow connected jika setiap dua titik yang berbeda dihubungkan oleh rainbow path. Suatu pewarnaan sisi di mana $G$ adalah rainbow connected dikatakan rainbow coloring. Bilangan rainbow connection dari graf terhubung $G$, ditulis $r c(G)$, didefinisikan sebagai minimum dari banyaknya warna yang diperlukan untuk membuat $G$ menjadi rainbow connected. Suatu rainbow coloring yang menggunakan $r c(G)$ warna dikatakan sebagai minimum rainbow coloring [4].

Konsep rainbow connection dapat digunakan untuk pengamanan pengiriman informasi rahasia antar pemerintah dan agen. Dalam hal ini, pemerintah dan agen tidak diizinkan untuk saling mencek informasi karena berhubungan dengan keamanan nasional, sehingga informasi kepada agen satu dan lainnya harus menggunakan sandi. Dengan demikian, akan terdapat satu atau lebih lintasan informasi 
untuk setiap dua agen dan harus dipastikan tidak ada sandi yang berulang. Kata sandi setiap lintasan harus berbeda, sehingga harus ditentukan jumlah sandi yang dibutuhkan, agar terdapat satu lintasan yang aman antara dua agen. Situasi inilah yang dimodelkan dalam bilangan rainbow connection. Pada penelitian ini akan dibahas tentang bilangan rainbow connection dari suatu graf $G$ dengan memperhatikan sifat-sifat tertentu dari komplemen graf tersebut.

\section{Definisi dan terminologi dalam graf}

Suatu graf $G$ didefinisikan sebagai pasangan terurut himpunan $(V(G), E(G))$ dengan $V(G)$ adalah himpunan tidak kosong yang berhingga dengan elemenelemennya dinamakan titik (vertex) dan $E(G)$ adalah himpunan sisi (edge) yang menghubungkan sepasang titik [6]. Komplemen dari suatu graf $G$, ditulis $\bar{G}$, yaitu suatu graf di mana jika $u v \in E(G)$ maka $u v \notin E(G)$ untuk setiap $u, v \in V(G)[6]$.

Graf reguler adalah graf yang semua titiknya berderajat sama. Graf reguler dengan banyak $n$ titik dan derajat setiap titiknya adalah $r$, dinotasikan dengan $r$-reguler. Graf lingkaran (cycle) adalah graf terhubung 2-reguler. Graf lingkaran dengan $n$ titik dinotasikan dengan $C_{n}[7]$. Contoh graf $C_{n}$ diperlihatkan pada Gambar 2.1.

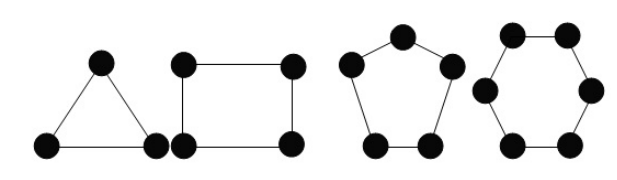

Gambar 2.1. Graf lingkaran $C_{n}$ dengan $3 \leq n \leq 6$.

Graf buku $B_{n}$ (book graph) adalah graf hasil kali cartesian $S_{n+1} \times P_{2}$, di mana $S_{n}$ adalah suatu graf bintang dan $P_{2}$ adalah graf lintasan dengan dua titik. Contoh graf buku dapat dilihat pada Gambar 2.2.

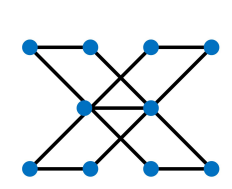

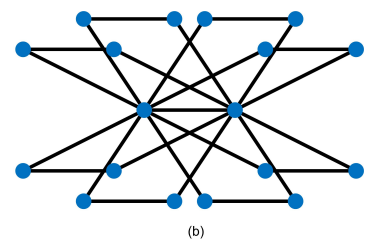

Gambar 2.2. (a) Graf $B_{4}$, (b) Graf $B_{8}$. 


\section{Hasil dan Pembahasan}

Teorema 3.1. Misalkan $G$ adalah suatu graf terhubung, di mana $G \simeq C_{n}$ atau $G \simeq B_{2}$. Maka bilangan rainbow connection dari graf $\bar{G}$ adalah

$$
r c(\bar{G})=\left\{\begin{array}{l}
2, \text { untuk } G \cong C_{n} \text { dengan } n \geq 6 \\
3, \text { untuk } G \cong B_{2} .
\end{array}\right.
$$

Bukti. Perhatikan dua kasus berikut.

Kasus 1. Untuk $G \cong C_{n}$ dengan $n \geq 6$.

Untuk setiap $C_{n}$ dengan $n \geq 6$, jelas bahwa $\operatorname{diam}\left(\bar{C}_{n}\right)=2$. Sehingga, $\operatorname{rc}\left(\bar{C}_{n}\right) \geq 2$. Selanjutnya, akan ditunjukkan bahwa $r c\left(\bar{C}_{n}\right) \leq 2$. Karena $C_{n}$ adalah graf 2-reguler, maka $\bar{C}_{n}$ adalah graf tidak lengkap. Akibatnya, terdapat dua titik, sebut titik $u$ dan titik $v$, yang tidak bertetangga. Selanjutnya, karena $d(x) \geq n-2$ untuk setiap $x \in V\left(\bar{C}_{n}\right)$ dengan $n \geq 6$, maka $d(x) \geq 3$. Jadi, terdapat satu titik $w$ di $V\left(\bar{C}_{n}\right)$ yang bertetangga dengan $u$ dan juga dengan titik $v$. Akibatnya, terdapat rainbow path $u P v$ dengan $|u P v|=2$, sehingga $r c\left(\bar{C}_{n}\right) \leq 2$. Jadi, $r c\left(C_{n}\right)=2$. Agar terdapat rainbow path pada graf $\bar{G}$ maka minimum dari warna yang diberikan pada rainbow path adalah dua, sehingga $\operatorname{rc}(\bar{G})=2$.

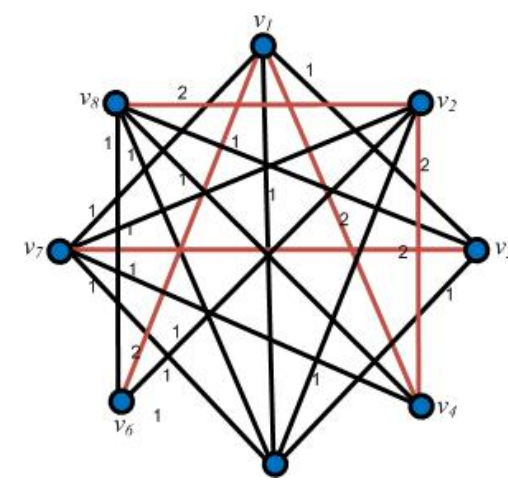

Gambar 3.1. Graf $\bar{C}_{8}$.

Kasus 2. Untuk $G \cong B_{2}$.

Misalkan $n=2 k$ dengan $k=3$. Pertama akan ditunjukkan $r c(\bar{G}) \leq 3$. Definisikan pewarnaan

$$
c(e)=\left\{\begin{array}{l}
1, \text { jika } e=v_{1} v_{6}, v_{1} v_{3} \text { dan } v_{3} v_{4} \\
2, \text { jika } e=v_{2} v_{6}, v_{4} v_{6}, v_{1} v_{5}, v_{3} v_{5} \\
3, \text { jika } e=v_{2} v_{4}
\end{array}\right.
$$

Dari definisi pewarnaan pada $\bar{B}_{2}$ tersebut, diperoleh $\operatorname{rc}\left(\bar{B}_{2}\right) \leq 3$ untuk $n=3$. Perhatikan bahwa diam $\left(\bar{B}_{2}\right)=3$, sehingga $\operatorname{rc}\left(\bar{B}_{2}\right) \geq 3$. Oleh karena itu $\operatorname{rc}\left(\bar{B}_{2}\right) \geq 3$. Jadi, $\operatorname{rc}\left(\bar{B}_{2}\right)=3$. 


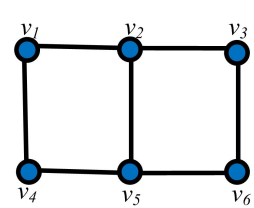

(a)

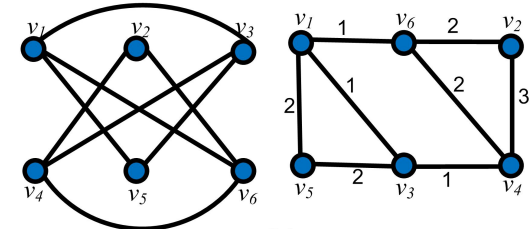

(b)

Gambar 3.2. (a) Graf $B_{2}$, (b) Graf $\bar{B}_{2}$.

\section{Ucapan Terima kasih}

Penulis mengucapkan terima kasih kepada Bapak Dr. Syafrizal Sy, Ibu Dr. Lyra Yulianti, Bapak Dr. Admi Nazra, Bapak Dr. Muhafzan dan Bapak Dr. Mahdhivan Syafwan, yang telah memberikan masukan dan saran sehingga paper ini dapat diselesaikan dengan baik.

\section{Daftar Pustaka}

[1] J.A. Bondy, dan Murty, U.S.R. 2008. Graph Theory, Graduated Texts In Mathematics. Springer. New York.

[2] Y. Caro, A. Lev, Y. Roditty, Z. Tuza, R. Yuster. 2008. On rainbow connection, Electronic J. Combin, 15, R57.

[3] L.S. Chandran, A. Das, D.Rajendraprasad, N.M. Varma. 2010. Rainbow connection number and connected dominating sets, ArXIv: 1010.2296v1 [math.CO].

[4] G. Chartrand, G.L. Johns, K.A. McKeon, P. Zhang. 2008. Rainbow connection in graphs, Math. Bohem. 133: 85-98.

[5] Chartrand. dkk. 2005. Introduction to Graph Theory, McGraw-Hill. Boston.

[6] Diestel, Reinhard. 2005. Graph Theory, Electronic Edition 3. New York.

[7] X. Li dan Y. Sun. 2010. Rainbow connection numbers of complementary graphs, arXiv:1011.4572v3 [math.CO]. 